Linguagem em (Dis)curso, Palhoça, SC, v. 9, n. 3, p. 565-583, set./dez. 2009

\title{
CONSIDERAÇÕES SOBRE A INTERTEXTUALIDADE NO HIPERTEXTO*
}

\author{
Júlio César Araújo* \\ Ana Cristina Lobo-Sousa ${ }^{* * *}$
}

\begin{abstract}
Resumo: Os trabalhos que caracterizam o hipertexto apontam a intertextualidade como uma característica que lhe é inerente, no sentido de levar a um novo texto, dada a presença dos hiperlinks. Considerando-se que a intertextualidade é um fenômeno linguístico-discursivo que relaciona os dizeres e se manifesta em sentido amplo e em sentido restrito, este trabalho indaga "em que sentido se está caracterizando o hipertexto como intrinsecamente intertextual". Em nossa reflexão, percebemos o fenômeno intertextual como sendo descrito apenas em função da justaposição de textos pelos hiperlinks, desconsiderando-se as relações de sentido entre eles e as diferenças existentes entre o que ocorria com o mesmo fenômeno no âmbito do texto.
\end{abstract}

Palavras-chave: intertextualidade; hipertexto; hiperlink.

\section{CONSIDERAÇÕES INICIAIS}

Nos trabalhos que se dedicam a caracterizar o hipertexto, é comum encontrarmos discussões e pesquisas sobre a intertextualidade como um atributo que lhe é inerente, no sentido de levar a um outro texto (XAVIER, 2002, 2003, 2007; KOCH, 2003, 2008; KOMESU,

\footnotetext{
* Trabalho oriundo do projeto Gêneros digitais: relações entre bipertextualidade, propósitos comunicativos e ensino, em desenvolvimento no grupo de pesquisa Hiperged, do PPGL da UFC. Agradecemos a Carla Viana Coscarelli (UFMG), a Ana Elisa Ribeiro (CEFET-MG) e ao Valdinar Custódio Filho (UFC) pelas contribuições dadas ao nosso trabalho quando leram as primeiras versões do texto. Responsabilizamo-nos pelos problemas remanescentes.

** Professor do Programa de Pós-Graduação em Linguística da Universidade Federal do Ceará, Fortaleza, CE, Brasil. Coordenador do grupo de pesquisa Hiperged. Doutor em Linguística. Email: $<$ araujo@ufc.br>. Site pessoal: <www.julioaraujo.com>.

*** Membro do grupo de pesquisa Hiperged-UFC, Fortaleza, CE, Brasil. Mestre em Linguística. Email: <crisloup@gmail.com>.
} 
2005; SILVA, 2006; GOMES, 2007, para citar alguns). Nesses trabalhos, o conceito de intertextualidade parece ser abordado em sentido amplo, no qual os conceitos de texto e de discurso se sobrepõem e, além disso, confunde-se com o conceito de hipertextualidade, considerando que um texto liga-se, literalmente, pela hiperlinkagem, a outro(s) texto(s).

Este artigo indaga em que sentido se está considerando o hipertexto como intrinsecamente intertextual. Não pretendemos, é claro, e como se poderia pensar, negar um pressuposto tão inconteste quanto o do dialogismo bakhtiniano, segundo o qual todo discurso é essencialmente dialógico, porque "sempre responde (no sentido lato da palavra), de uma forma ou de outra, a enunciados do outro anteriores" (BAKHTIN, [1953] 1997, p. 319). A indagação se justifica, contudo, porque, ao se considerar o hipertexto como intrinsecamente intertextual, não se faz outra coisa senão afirmar redundantemente que todo dizer é um já-dito, o que pouco contribui para o entendimento da complexidade do fenômeno intertextual em si.

A partir dessas considerações, neste texto, refletiremos sobre o que se tem entendido por intertextualidade no hipertexto, na tentativa de discutir especificamente sobre os parâmetros pelos quais se define a intertextualidade no hipertexto. De fato, compreendemos que a intertextualidade é constitutiva não só do texto, ou do hipertexto, mas da linguagem humana. O que contestamos é que a análise do fenômeno intertextual no hipertexto se restrinja a uma abordagem que se limite a ressaltar essa premissa básica da linguagem viabilizada agora pela presença de biperlinks, impedindo, assim, que se avance numa operacionalização da categoria de intertextualidade no hipertexto.

Partimos, então, da ideia de que o fenômeno intertextual tem se confundido com a hipertextualidade, na medida em que a consideração da intertextualidade como atributo do hipertexto limita-se à descrição da justaposição de textos, sem, contudo, particularizar o tipo de relação estabelecida entre os textos, que pode ser, segundo Gomes (2007), de expansão, relação parte/todo, nota, ilustrações, definições, resumos etc.

Considerando que a linguística textual vem assumindo como prática investigativa uma análise intertextual que privilegia a remissão de um texto a outro(s) texto(s) que compõe(m) a memória sociodiscursiva dos leitores/ouvintes, cumpre-nos verificar se tal prática se aplica ao 
hipertexto. Acreditamos que investir nessa reflexão é relevante para que as noções de hipertextualidade e de intertextualidade não se confundam e nem se tome de maneira muito genérica um fenômeno tão complexo e importante para a compreensão leitora, como o é a intertextualidade.

Para esse exercício de análise, faremos uma breve discussão sobre intertextualidade em sentido amplo e em sentido restrito, a fim de compreender o entrelaçamento dos termos texto e discurso. Essa primeira seção será ancorada nos preceitos bakhtininanos sobre o discurso, retomados por Kristeva (1969), e na orientação tipológica de intertextualidade estabelecida por Genettte (1982). A seguir, na segunda seção, refletiremos sobre os parâmetros que definem a intertextualidade no hipertexto, tomando como referencial teórico Xavier (2002, 2003, 2007), por encontrar-se neste autor uma primeira proposta tipológica do fenômeno intertextual aplicada ao hipertexto. A tipologia de intertextualidade de Koch, Bentes e Cavalcante (2007) também nos dará suporte aqui.

Durante essa reflexão, consideraremos que enunciar no hipertexto é uma atividade cuja realização exige uma postura que não apenas considere aspectos como o tempo/espaço da enunciação, mas também mescle os gestos de ler e escrever herdados do texto impresso com os recursos hipermodais integrados e hibridizados em diferentes dizeres que se discursivizam, e se apresentam, na tela. Resta-nos dizer que, no presente artigo, o hipertexto é considerado como um modo de enunciação digital (XAVIER, 2002, 2003, 2007; BRAGA, 2005; ARAÚJO, 2006 e outros), por entendermos tratar-se de um jeito de dizer que encontra no suporte informático possibilidades além das permitidas pela superfície bidimensional do papel, na medida em que consegue mesclar modos enunciativos diversos, como a imagem, o som e a palavra, de maneira dinâmica e flexível graças ao espaço multidimensional.

\section{ENTRELAÇAMENTO INTERTEXTUAL: TEXTO OU DISCURSO?}

Sabe-se que o postulado do dialogismo bakhtiniano, segundo o qual todo discurso é essencialmente dialógico, por representar sempre 
uma resposta ou uma antecipação ao discurso do outro, é propagado por Kristeva (1969, p. 85), na célebre citação que inaugura a primeira definição de intertextualidade: "todo texto se constrói como um mosaico de citações, todo texto é a absorção e transformação de um outro texto" $"$.

Note-se que essa definição seminal de intertextualidade proposta por Kristeva (1969) no seio da Teoria Literária é oriunda das reflexões de Bakhtin ([1929] 2004) que tomam como unidade de análise o discurso e não o texto. Essa consideração é importante porque segundo Kristeva, qualquer texto é um conjunto de outros textos, muitas vezes inconscientes; logo, o intertexto, ou seja, aquilo que se possa perceber da relação de dois textos, pode não ser um objeto facilmente recuperável ou perceptível, mas estar diluído por todo o texto ou, ainda, a partir dele.

Tal concepção faz coro com o que, no âmbito da Análise do Discurso, é definido por Authiez-Revuz (2004) como heterogeneidade discursiva, ou seja, o texto é uma unidade aparentemente fechada, que reflete e refrata o discurso do outro, de maneira mais ou menos nítida, a depender da natureza do discurso. A autora distingue heterogeneidade constitutiva do discurso (não-identificável) de heterogeneidade mostrada que pode ser marcada ou não-marcada ${ }^{2}$. Sendo assim, tratar dos diálogos entre textos adquire conotações distintas se tomamos como unidade de análise o texto ou o discurso, este último, sem dúvida, permitindo uma análise mais ampla.

Uma análise intertextual mais restritiva pode ser percebida na tipologia proposta por Genette (1982) em Palimpsestes ${ }^{3}$. O autor se refere a "relações de transtextualidade", como tudo aquilo que coloca o texto em relação manifesta ou secreta com outros textos, ultrapassando assim a unidade textual de análise. Embora se valendo do paradigma terminológico fornecido por Kristeva (1969), Genette (1982) prefere

\footnotetext{
${ }^{1}$ Tradução nossa de: "tout texte se construit comme mosaique de citations, tout texte est absorption et transformation d'un autre texte".

2 A heterogeneidade mostrada é marcada quando se percebe sua presença no discurso e a ele se reporta, com expressões como, por exemplo, "como diz o outro", "se me permito dizer" entre outras. A heterogeneidade é não-marcada quando se espera que o interlocutor infira o jogo de vozes, a exemplo do que se tem no discurso indireto livre, na ironia etc.

${ }^{3}$ Palimpsestes, conforme ensina Bezerra (2007, p. 20), significa "raspados de novo". Trata-se, segundo o autor, de uma técnica para reutilização de manuscritos antigos em pergaminho.
}

ARAÚJO; LOBO-SOUSA - Considerações sobre a intertextualidade... 
definir a intertextualidade como "uma relação de co-presença entre dois ou vários textos", isto é, "pela presença efetiva de um texto no outro ${ }^{4}$ ", (GENNETE, 1982, p. 8).

Assim, a intertextualidade, presença mais ou menos explícita de um texto no outro, cujo exemplar mais enfático é a citação, constitui apenas um dos cinco tipos de relações transtextuais, que são, segundo o autor, a arquitextualidade, quando um texto se adéqua a um determinado gênero, a paratextualidade, relação de um texto com seus paratextos (prefácio, ilustrações etc.), a metatextualidade, quando um texto comenta outro, numa relação crítica; e a bipertextualidade, caso da paródia e do pastiche, em que ocorre uma relação de derivação de um texto originário.

Entretanto, os limites de uma abordagem e de outra frequentemente se entrecruzam, fato reconhecido pelo próprio autor, ao afirmar que seus tipos de transtextualidade não devem ser considerados como classes estanques, sem comunicação nem recortes recíprocos. Para o autor, essas "relações são ao contrário numerosas e geralmente decisivas" (GENNETE, 1982, p. 16).

Diante desse quadro, a linguística textual incorpora o postulado dialógico de Bakhtin ([1929] 2004, [1953] 1997), de que um texto (enunciado) está sempre em diálogo com outros textos, para relacionar ao fenômeno intertextual em sentido amplo (lato sensu), constitutivo de todo e qualquer discurso como tacitamente aceito. Na prática, porém, o fenômeno intertextual é analisado em sentido restrito (stricto sensu), quando um texto remete a outros textos efetivamente produzidos, sendo necessária, portanto, a presença de um intertexto, um já-dito que faz parte da memória discursiva dos leitores/ouvintes, ainda que alguns destes não o reconheçam.

Essa definição menos abrangente de intertextualidade permite depreender da unidade de análise texto, marcas linguísticas que se relacionam a formas e conteúdos de outros textos. Essas marcas linguísticas, de acordo com Koch (1997) e Koch, Bentes e Cavalcante (2007), vão além do lexema, independentemente do nível de estruturação. A esse respeito, Cavalcante (2007, p. 1), observa que "não

\footnotetext{
${ }^{4}$ Tradução nossa de: "[...] une relation de cópresence entre deux ou plusiers textes, c'est-a-dire, eidétiquement et le plus souvent, par la présence effective d'un texte dans un autre".

${ }^{5}$ Tradução nossa de: "Leurs relations sont au contraire nombreuses, et souvent décisives".
} 
importa o tipo de remissão - se ao léxico, se a estruturas fonológicas, a estruturas sintáticas, ao gênero, ao estilo, ao tom", o importante é que o co-enunciador consiga reconhecer a interseção de textos ou o intertexto.

Vale ressaltar que é imperativo, numa análise intertextual em sentido restrito, a co-presença de textos, que pode ser reconhecida ou não pelo interlocutor, mas que se refere a um já-dito, portanto, a algo preexistente, denominado intertexto, o qual é apreendido por marcas linguísticas; fato que pode ser demonstrado no criativo anúncio a seguir:
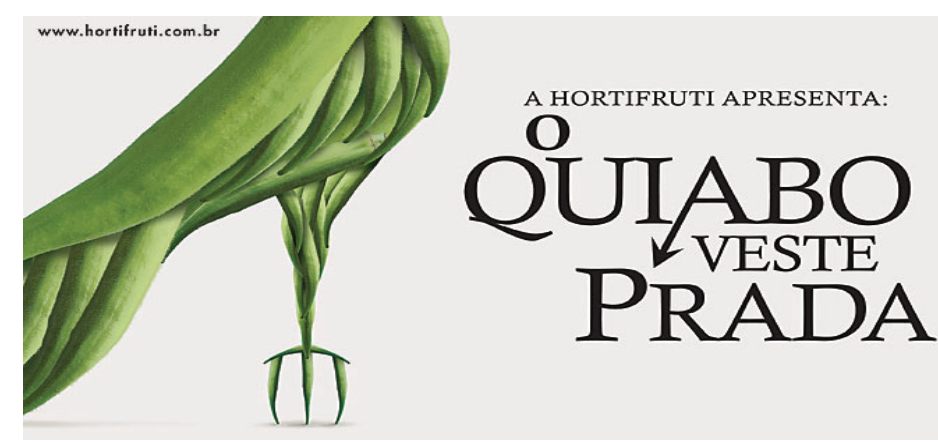

ELE ENTROU NO SELETO MUNDO DA HORTIFRUTI.

Figura 1 - Anúncio publicitário.

Neste exemplo ${ }^{6}$, tem-se uma paráfrase com o título do livro $O$ Diabo veste Prada, de Lauren Weisberger ${ }^{7}$ e, portanto, com o filme de mesmo nome. O intertexto pode ser depreendido não só pela frase em destaque, como também pela imagem do legume à esquerda. Assim, independentemente do grau de explicitude, observa-se como critério para a intertextualidade em sentido restrito a construção textual a partir de um já-dito. Pode-se imaginar que, diante do enunciado "O quiabo veste prada", lembramos do título de um livro ou filme. Esse movimento retrospectivo, de reportar-se a algo já visto ou ouvido, é o que caracteriza o reconhecimento do intertexto.

É particularmente essa delimitação, a de reconhecer empiricamente um intertexto mais ou menos demarcado, que irá nortear as investigações sobre intertextualidade na linguística textual no âmbito do texto. O que não sabemos ainda é se essa mesma escolha

\footnotetext{
${ }^{6}$ Disponível em: <http://www.mppublicidade.com.br>.

7 Sobre o livro referido, ver, além de outros, o endereço: <http://www.digestivocultural. com/ensaios/ensaio.asp?codigo $=177>$.
} 
metodológica é a que se aplica quando o objeto em análise é o hipertexto.

\section{UMA TIPOLOGIA HIPERINTERTEXTUAL?}

Xavier (2003), em artigo destinado a refletir sobre o fenômeno intertextual no hipertexto, propõe o termo "hiperintertextualidade infinita". Neste trabalho, o linguista relaciona a inter-relação entre os dizeres, condição de existência de qualquer texto ou discurso, à hipertextualidade, numa tipologia fundamentada em Koch (1990), para quem haveria dois tipos de intertextualidade, uma de forma e outra de conteúdo.

Em sua explicação,

a primeira ocorre quando o produtor de um dado texto repete expressões, enunciados e trechos de outros textos. Já a intertextualidade de conteúdo se realiza no interior de uma mesma cultura, por meio de textos de uma mesma época e áreas de conhecimento. A intertextualidade de conteúdo pode se dar explícita ou implicitamente. (XAVIER, 2003, p. 285 - gf. do autor)

Segundo o autor, no caso de hipertextos, é mais frequente ocorrer a intertextualidade explícita, já que os biperlinks são estrategicamente construídos para levar o hiperleitor a lugares outros na rede. Para ratificar sua descrição, o autor exemplifica com o site de Rubem Alves (www.rubemalves.com.br.), exemplo que ilustramos a seguir, ainda que com alterações na página citada inicialmente decorrentes da fluidez constitutiva do ambiente digital. Essas alterações, entretanto, em nada divergem daquilo que se pretende argumentar aqui ${ }^{8}$.

De acordo com Xavier (2003), uma vez clicando-se sobre um dos biperlinks ${ }^{9}$, representados pelos enunciados à direita da figura e na cor branca, e indo a outros hipertextos, realiza-se a intertextualidade explícita ou a hiperintertextualidade. Antes, havia o hiperlink, representado pelo

\footnotetext{
${ }^{8}$ Para conferir o exemplo citado, ver bibliografia ao final deste trabalho.

${ }^{9}$ No exemplo de Xavier (2003), havia outros enunciados na cor preta em um quadro branco posicionados também à direita da página inicial do site.
} 
enunciado: "Se você gostou da minha casa", que levava o hiperleitor ao site da empresa que confeccionara o site do psicanalista. Hoje, nenhum dos hiperlinks presentes acima leva a outros sites, com exceção dos que se posicionam acima e abaixo da tela, numa barra azul, referentes ao provedor que hospeda o site, neste caso, o provedor wmw.uol.com.br. Todos os enunciados, que vão de "Novidades" a "Loja virtual", são hiperlinks que permitem apenas a navegação dentro do mesmo site, a maioria levando a textos do autor.

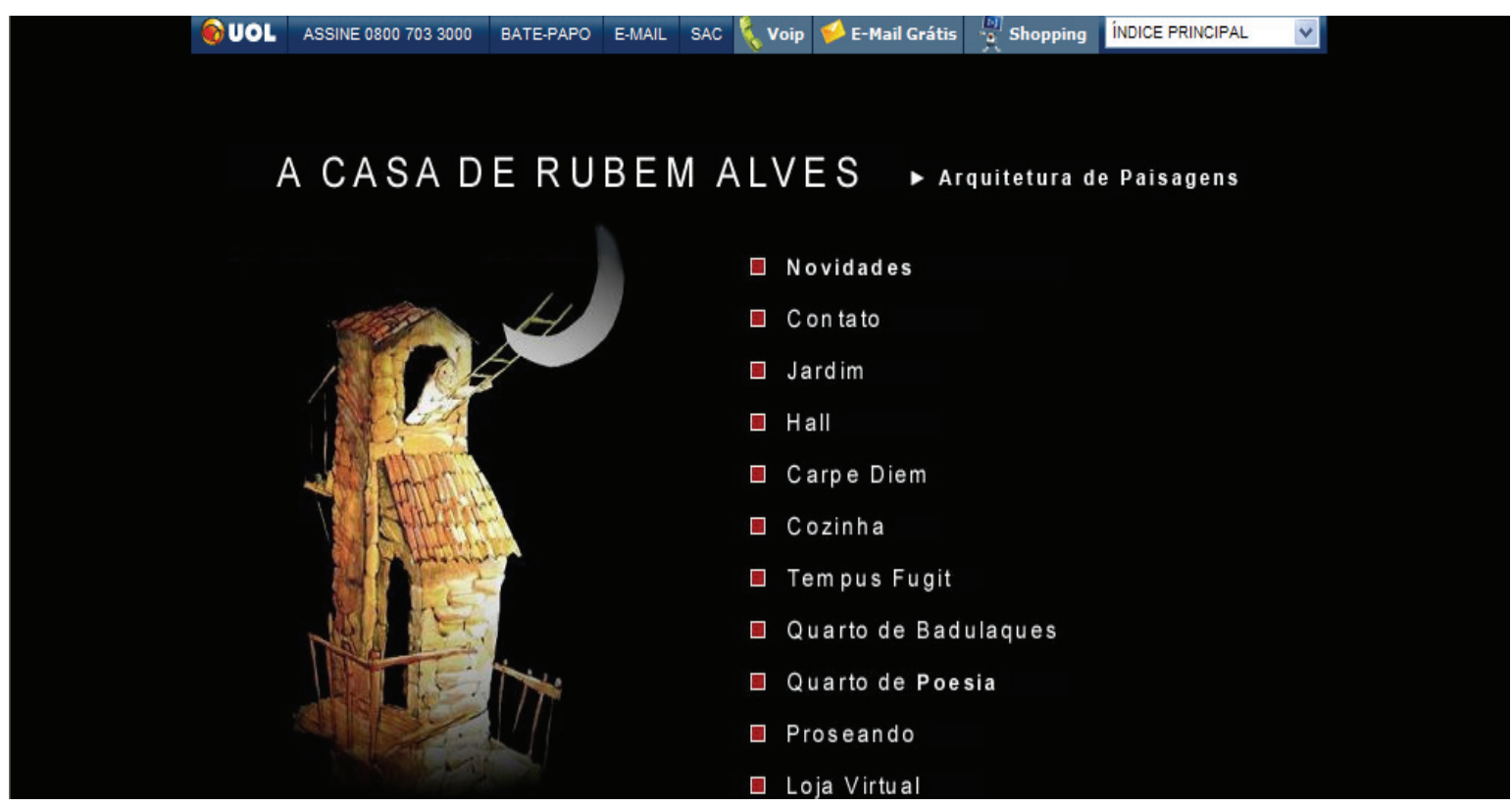

Figura 2 - Homepage de Rubem Alves.

Não fica claro, portanto, que tipo de intertextualidade daria conta dessas evidências empíricas. No entanto, o que parece ficar mais ou menos evidente na explicação de Xavier (2007) é que a intertextualidade que se realiza no hipertexto pelos biperlinks é a de conteúdo, por referirse a temas comuns ou diversos, e a do tipo explícita, por levar a outros hipertextos.

Como se pode notar, o primeiro equívoco está em adotar os critérios classificatórios forma e conteúdo como elementos dissociados. Aliás, a própria Koch (1997), à época do referido artigo de Xavier (2003), já havia revisto tal classificação, descartando a possibilidade de uma intertextualidade apenas de forma, uma vez que toda forma enforma/emoldura um conteúdo. 
Um segundo problema que se apresenta decorre da definição de intertextualidade de conteúdo do tipo explícita com base nos dispositivos informáticos, comumente denominados biperlinks, apenas considerados do ponto de vista material como elementos interconectores de textos ou de fragmentos de textos. Não há qualquer consideração acerca do conteúdo que é linkado, mas apenas a descrição de um movimento que é próprio da informática, ou seja, o clique.

Essa consideração negligencia, de acordo com Braga (2005), os diversos sentidos estabelecidos pelos links, que vão desde associações semânticas a comentários mais aprofundados. Segundo a autora, as ligações estabelecidas pelos hiperlinks vão além de expansões ou relações secundárias, passando a ser centrais na estruturação do texto, já que as próprias relações estabelecidas pelos hiperlinks passam a ser parte constitutiva de seu sentido ${ }^{10}$.

Além disso, se o aporte teórico do hipertexto adotado por Xavier (2002, 2003) é o dialogismo bakhtiniano, é de se supor que uma análise intertextual seja mais abrangente que uma abordagem centrada na biperlinkagem. Fica confuso admitir que os critérios pelos quais se define a intertextualidade no hipertexto sejam forma e conteúdo, estes sendo tomados separadamente.

Em uma tipologia mais recente de intertexto, Koch, Bentes e Cavalcante (2007, p.17) descrevem quatro tipos de intertextualidade stricto sensu, ou seja, "quando, em um texto, está inserido outro texto (intertexto) anteriormente produzido, que faz parte da memória social de uma coletividade ou da memória discursiva dos interlocutores".

O primeiro tipo de intertextualidade, denominado temática, ocorre quando textos diversos partilham de temas e se servem de conceitos e terminologias próprios, como entre matérias de jornais. O segundo tipo, intertextualidade estilística, ocorre quando o produtor do texto, com objetivos variados, repete, imita, parodia certos estilos ou variedades

\footnotetext{
10 Não obstante isso, em alguns hipertextos os hiperlinks, muitas vezes, têm função mais navegacional do que textual, conforme salientam Gomes (2007) e Gualberto (2008, p.18). Esta última mostrou, por exemplo, que "o termo que está materializado no hiperlink, poderá estimular ou inibir a navegação ou acesso do usuário a determinados blocos textuais, produzindo assim interferências na construção de sentidos na leitura de um hipertexto". Trabalhos como esses, ajudam-nos a nos perguntar se realmente é seguro afirmar que link é sinônimo de intertextualidade.
} 
linguísticas. A intertextualidade explícita, o terceiro tipo, se dá quando, no próprio texto, é feita menção à fonte do intertexto, como em citações, resumos, resenhas. Por fim, o quarto tipo, é a intertextualidade implícita, que ocorre quando se introduz, no próprio texto, intertexto alheio, sem qualquer menção explícita da fonte, como se tem na paródia ou no plágio.

Essa tipologia, diferentemente da estabelecida por Genette (1982), para quem a paródia e o plágio, exemplos mais emblemáticos de intertextualidade, não são contemplados como intertextuais, e, sim, como transtextuais, não apresenta critérios homogêneos em sua classificação, como se pode aferir numa leitura mais atenta. Essa observação, aliás, foi realizada por Cavalcante (2007) ao afirmar que os critérios pelos quais se define a intertextualidade do tipo temática orientam-se pelo conteúdo, sendo este entendido como uma unidade total que é repetida em outro, ao passo que a intertextualidade do tipo estilística orienta-se pelos critérios forma/conteúdo. Desse modo, a distinção da intertextualidade do tipo explícita da intertextualidade implícita reside nos critérios de marcação ou não-marcação da fonte do intertexto.

Quando, porém, a unidade em análise é o hipertexto, essa tipologia intertextual aplicada ao texto não tem sido considerada. Tudo o que temos é a premissa segundo a qual o hipertexto é intertextual. Porém, se durante uma navegação, seja num mesmo hipertexto ou em hipertextos diversos, ao clicar sobre um biperlink, se realiza a intertextualidade, então se admite, ao menos implicitamente, que a presença de hiperlinks confere e garante a intertextualidade ao hipertexto, embora a ressalva "se os hipertextos estiverem indexados à rede" seja feita por Xavier (2002, p.32).

Nesta consideração, entretanto, não se observa a relação temática que interliga textos, mas simplesmente o fato de estarem interligados, o que só pode se enquadrar na prática, num sentido amplo de intertextualidade. E essa intertextualidade, por ser constitutiva da linguagem, nada acrescenta, em termos de análise, à compreensão do fenômeno intertextual no hipertexto. Com efeito, a intertextualidade em sentido amplo sempre se manifestará, independentemente do movimento produzido pela hiperlinkagem, afinal, há a intertextualidade não-marcada, já observada por Komesu (2005), a qual é igualmente constitutiva da heterogeneidade da linguagem. 
Também Koch (2003, 2008), ao afirmar que o hipertexto é, por sua própria natureza, essencialmente intertextual, por se tratar de inúmeros textos que se fundem e se sobrepõem a inúmeros textos simultaneamente, leva-nos a concluir que, ao considerar a função remissiva do hiperlink como a própria concretude da intertextualidade no meio digital, estaria pressuposto que os já-ditos, uma vez reconhecidos, estariam interconectados pela hipertextualidade. Se for assim, levantamos as seguintes indagações: textos conectados por biperlinks são necessariamente intertextuais, do ponto de vista restrito, ou apenas hipertextuais? De que ponto de vista se está falando?

Se os parâmetros que definem a intertextualidade no hipertexto se ancoram apenas na sua biperlinkagem, várias são as razões para se propor uma nova reflexão que leve a uma caracterização mais clara do fenômeno, o que poderá ser uma contribuição para ao menos atenuar as confusões terminológicas entre intertextualidade e hipertextualidade. Certamente não é a sobreposição de textos que explica e garante a intertextualidade no hipertexto.

É curioso observar ainda que, enquanto no texto, o reconhecimento do intertexto leva a outro texto já conhecido - posto que é um já-dito -, no hipertexto, em geral, ocorre um movimento inverso. O hiperlink leva a um novo e, portanto, desconhecido texto, fato que se pode notar claramente em hipertextos contendo notícias, como no exemplo a seguir ${ }^{11}$, no qual as manchetes, em forma de perguntas do lado direito da tela, correspondem a biperlinks que, uma vez clicados, expandem o conteúdo da matéria e, logo, revelam o que, em princípio, não se sabe.

Neste exemplo da figura 3, a pergunta apontada pela seta à direita é apresentada com o restante de seu respectivo texto à esquerda e mais ao centro da tela. Verifica-se uma ampliação do mesmo texto em virtude do espaço, o que não merece a caracterização de intertextualidade de conteúdo de tipo explícita, visto que é uma técnica de indexação da informação. Se, porém, reconhecêssemos algo em seu conteúdo que nos remetesse a um texto anterior, então estaríamos diante de uma intertextualidade, em sentido restrito. O que observamos é que, quando isso acontece, dificilmente o intertexto é hiperlinkado pelos produtores de

${ }^{11}<$ http:www.jornaldedebates.ig.com.br>. 
hipertextos. Logo, a intertextualidade, em geral, não aparece marcada por hiperlinks, como se pode notar na figura 1 deste trabalho, em que a fonte inspiradora do anúncio não aparece imediatamente interligada ao texto, mas independente dela.

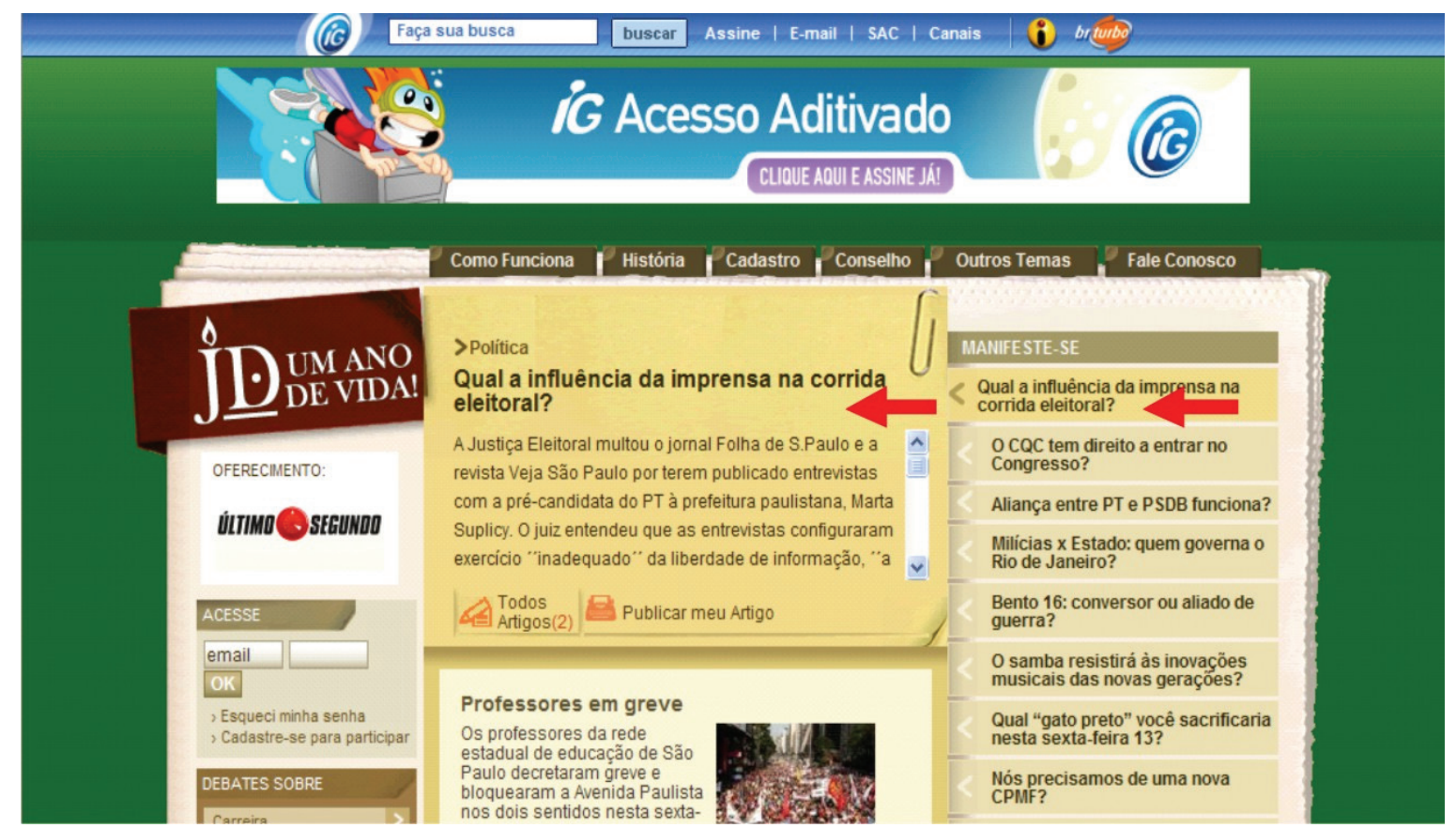

Figura 3 - Homepage Jornal de Debates.

Esses exemplos, e tantos outros que poderiam aqui ser ilustrados, permitem-nos discordar da afirmação de Xavier (2007), segundo a qual a intertextualidade é uma das características constitutivas da idéia inicial de um sistema interligado de textos. Do mesmo modo, torna-se pouco produtiva a afirmação do mesmo autor, para quem "a intertextualidade é executada 'concretamente' pelo leitor, pois a remissão é feita de modo direto e instantâneo, bastando apenas um clicar de mouse sobre o link desejado para se ter acesso ao hipertexto indexado à web" (XAVIER, 2007, p. 209).

Independentemente de qualquer tipologia, faz-se necessário produzir a hiperlinkagem a serviço da intertextualidade, ou seja, remetendo diretamente ao texto/dizer anterior; afinal, de acordo com Xavier (2002, 2003), os hiperlinks mostram o que estaria apenas em nossa memória discursiva. 
Diante do hipertexto, enquanto porção escolhida para a leitura/navegação, o que se tem na prática começa a corroborar a existência de uma intertextualidade "tecnológica", no sentido de indexar textos originalmente intertextuais, como se pode notar na figura a seguir, na qual digitamos "canção do exílio" no site de busca Google, como se pode verificar:

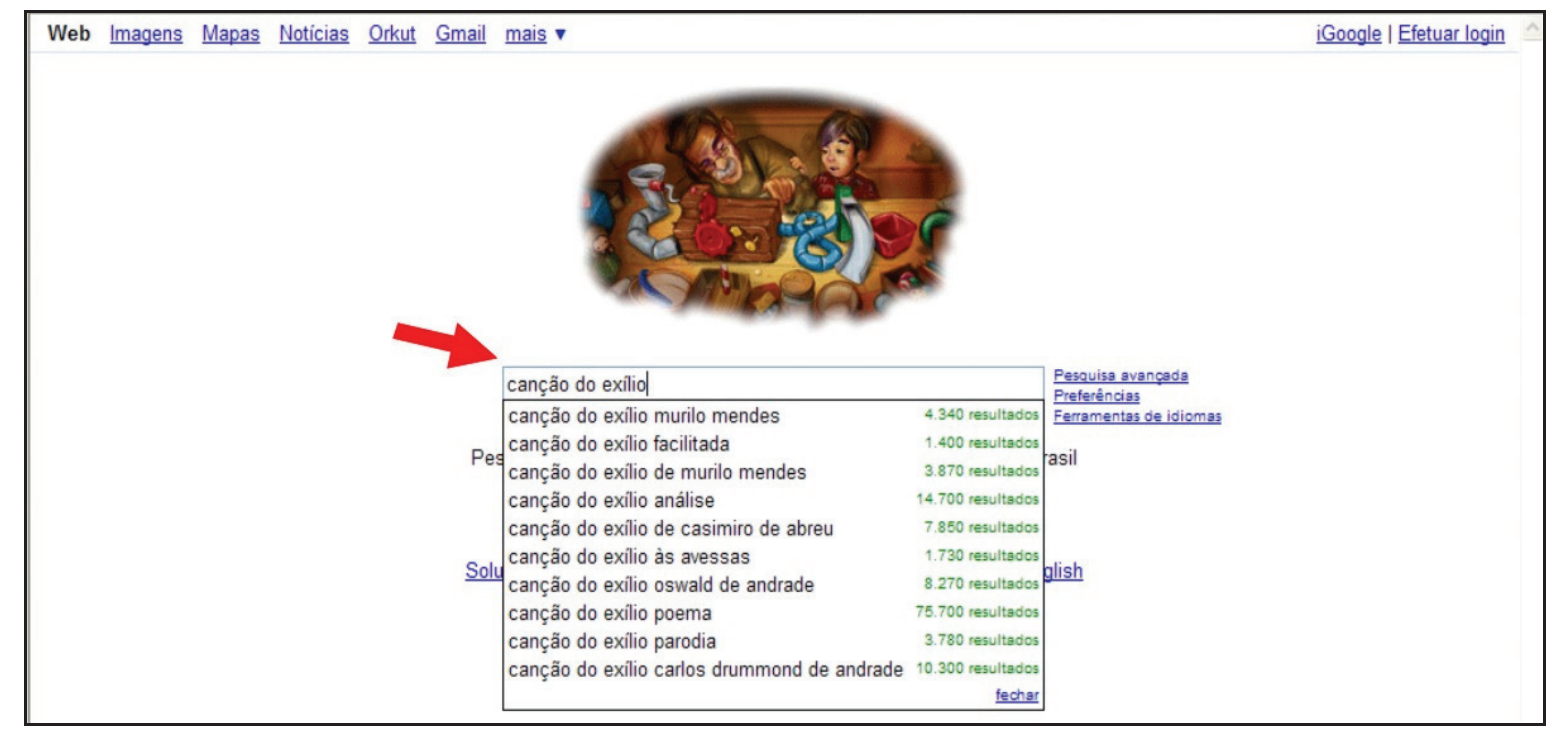

Figura 4 - Site de busca Google.

O texto "Canção do exílio", de Gonçalves Dias, é, segundo Koch, Bentes e Cavalcante (2007), um dos exemplos literários de intertextualidade - ora explícita, ora implícita - mais frequentemente citados. Não sem razão, o site Google, elenca entre as opções relacionadas à mesma expressão, sugestões como "Canção do exílio" de Murilo Mendes, de Casimiro de Abreu, de Oswald de Andrade, de Carlos Drummond de Andrade e outras. Clicando na primeira sugestão, a "Canção do exílio", de Murilo Mendes, vemos que não só temos a canção derivada de Gonçalves Dias, como também um hiperlink para a canção primitiva, como se vê na figura a seguir 5 .

Entretanto, a maioria dos hipertextos, por nós observados, apresentam textos que realizam claramente a intertextualidade com outros textos, porém não conectam o intertexto diretamente ao seu texto original, caso em que ocorre apenas justaposição de textos. Como observa Gomes (2007, p. 17), isso ocorre ainda porque "grande parte do conteúdo da web não foi produzido especialmente para ela", apenas tem 
se adaptado a ela, o que justifica a presença ainda de inúmeros hipertextos que em nada diferem de sua versão impressa. Essa adaptação ao novo suporte tem acontecido na medida em que a velocidade e o uso dos computadores têm aumentado.

\section{Canção do exílio}

\section{Minha terra tem macieiras da Califórnia} onde cantam gaturamos de Veneza.

Os poetas da minha terra são pretos que vivem em torres de ametista, os sargentos do exército são monistas, cubistas, os filósofos são polacos vendendo a prestações.

A gente não pode dormir com os oradores e os pernilongos.

Os sururus em familia têm por testemunha a Gioconda.

Eu morro sufocado em terra estrangeira.

Nossas flores são mais bonitas

nossas frutas mais gostosas

mas custam cem mil réis a dúzia.

Ai quem me dera chupar uma carambola de verdade e ouvir um sabiá con certidão de idade!

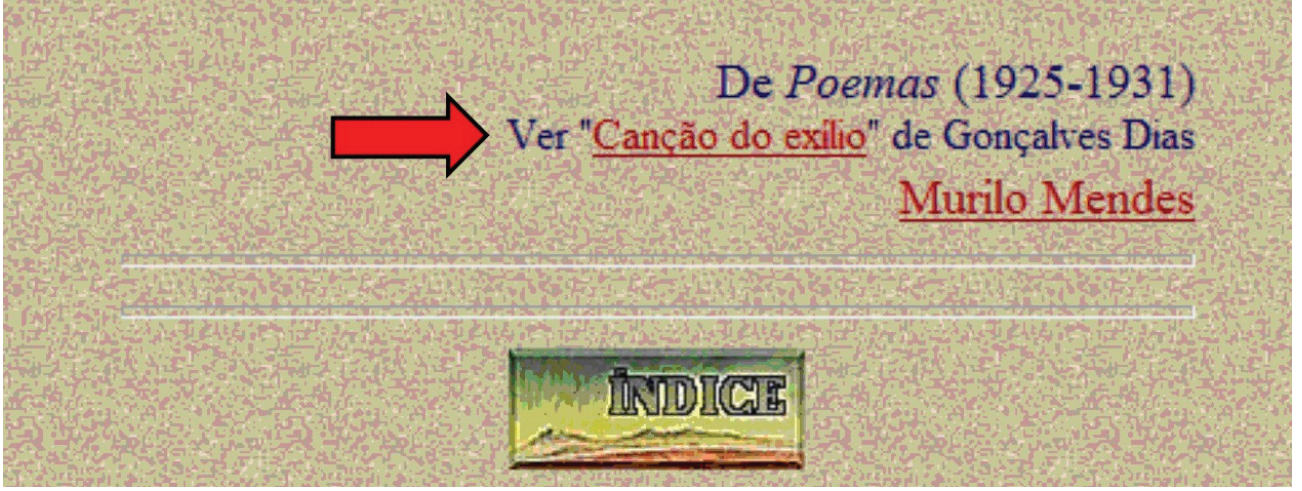

Figura 5 - Canção do Exílio de Murilo Mendes.

Diante disso, é válido afirmar que a intertextualidade, em sentido amplo, no hipertexto, ocorrerá, independentemente, da "biperlinkagem", visto que é não-marcada. Já a intertextualidade, em sentido restrito, 
poderá se manifestar em hipertextos e pelos hiperlinks, apesar de verificarmos muita superposição de textos para atender ao modo de indexar a informação, de maneira a tornar visível na tela um maior número de tópicos possíveis, como demonstrado aqui na figura 3. Por fim, sendo a intertextualidade um fenômeno que está além do hipertexto, vale indagar agora até que ponto ela o caracteriza. Não seria o caso de se verificar sua manifestação, independentemente do estatuto de critério definidor do hipertexto?

\section{CONSIDERAÇÕES FINAIS}

Na reflexão aqui esboçada, buscou-se demonstrar que a análise da intertextualidade no hipertexto tem se apoiado apenas no fato de se ter textos indexados na hipertextualidade, ou seja, apóia-se unicamente no dispositivo técnico-informático denominado hiperlink. Além disso, uma primeira tipologia do assunto estabelece critérios com base na oposição forma/conteúdo - já revista na linguística textual -, o que se pode avaliar como uma desconsideração do caráter descritivo novo que se enuncia no hipertexto, no qual os links levam a partes do mesmo texto, a outros textos, sejam eles já-ditos ou novos, e ainda, exercem, apenas, função navegacional, indicando, por exemplo, ir para frente ou retornar.

Por esses motivos, entende-se aqui que a afirmação, segundo a qual o hipertexto é, intrinsecamente, intertextual, (cf. KOCH, 2003, 2008), por se tratar de um texto 'múltiplo', cuja realização se dá pela fusão de inúmeros textos, apenas confirma uma premissa básica da linguagem amplamente difundida no postulado de Bakhtin ([1953] 1997), para quem nenhum discurso é proferido pelo Adão bíblico.

Enfim, pretendemos defender que uma análise da intertextualidade no hipertexto se mostrará mais produtiva se, a exemplo do que se tem feito no âmbito da linguística textual, procedermos a uma análise mais criteriosa, seja em sentido restrito, seja em sentido amplo, considerando as relações estabelecidas pelos biperlinks. Há que se considerar ainda que a reflexão aqui desenvolvida, mesmo ainda preliminar, aponta para uma hipótese de trabalho que merece ser mais explorada em trabalhos futuros. Qual seja: o hipertexto não garante a 
intertextualidade, pois o fato de linkar um texto a outro não garante, necessariamente, o fenômeno intertextual. Assim, podemos sugerir que o link, a rigor, gera a hipertextualidade e não a intertextualidade, pois o que percebemos é que a intertextualidade pode até ser explicitada em um link, mas não gerada por ele.

Certamente, somente investindo em pesquisa é que chegaremos a um aprofundamento empírico do fenômeno intertextual no hipertexto por meio do qual teremos como tecer afirmações mais consistentes. Porém, uma convicção se afigura firme: a de que muito se tem a desvendar quanto ao fenômeno intertextual no hipertexto, tendo em vista que na hipertextualidade diferentes esferas comunicativas cohabitam, nas quais diferentes gêneros podem possibilitar tipos diversos de intertextualidade (ARAÚJO, 2008). Nesse sentido, acreditamos que as pesquisas que pretendam lidar com a intertextualidade no hipertexto devem ir além da função remissiva dos hiperlinks para que não se escondam, por trás da obviedade, aspectos mais complexos da questão, pois, como disse Alós (2006, p. 11), "ao contrário do que vulgarmente possa se pensar, a noção de intertextualidade não faz do texto uma mera colagem de retalhos".

\section{REFERÊNCIAS}

ALÓS, A. P. Texto literário, texto cultural, intertextualidade. Revista virtual de estudos da linguagem - REVEL, Ano 4, n. 6, mar. 2006. Disponível em: <www.revelhp.ejb.net>. Acesso em: 10 dez. 2007.

ARAÚJO, J. C. Os chats: uma constelação de gêneros na internet. Tese (Doutorado em Linguística) - Programa de Pós-Graduação em Linguística, Universidade Federal do Ceará, 2006.

. As relações com a escrita: reflexões sobre o internetês. In: DIEB, M.

(Org.). Relações e saberes na escola: os sentidos do aprender e do ensinar. Belo Horizonte: Autêntica, 2008. p. 119-134.

AUTHIEZ-REVUZ. Entre a transparência e a opacidade: um estudo enunciativo do sentido. Porto Alegre: EDIPUCRS, 2004.

BAKHTIN, M. Estética da criação verbal. 2. ed. São Paulo: Martins Fontes, [1953] 1997.

ARAÚJO; LOBO-SOUSA - Considerações sobre a intertextualidade... 

[1929] 2004.

Marxismo e filosofia da linguagem. 11. ed. São Paulo: Hucitec,

BEZERRA, B. G. Do manuscrito ao livro impresso: investigando o suporte. In: CAVALCANTE, M.M. et al. (Orgs.). Texto, discurso sob múltiplos olhares - v. 1: gêneros e sequências textuais. Rio de Janeiro: Lucerna, 2007.

BRAGA, D. B. A comunicação interativa em ambiente hipermídia: as vantagens da hipermodalidade para o aprendizado no meio digital. In: MARCUSCHI, L. A.; XAVIER, A. C. (Orgs.). Hipertextos e gêneros digitais: novas formas de construção de sentido. 2. ed. Rio de Janeiro: Ed. Lucerna, 2005. p.144-162.

CAVALCANTE, M. M. Intertextualidade: critérios classificatórios. Mesaredonda realizada no 2. Encontro Linguístico e Literário do Mestrado em Letras da UFPI (EnMEL), Piauí, UFPI, 2007.

GENETTE, G. Palimpsestes: la littérature au second degré. Paris: Seuil, 1982.

GOMES, L.F. Hipertextos multimodais: o percurso de apropriação de uma modalidade com fins pedagógicos. Tese (Doutorado em Linguística Aplicada) IEL, Uninversidade Estadual de Campinas, 2007.

GUALBERTO, I. M. T. A influência dos hiperlinks na leitura de hipertexto enciclopédico digital. Tese (Doutorado em Estudos Linguísticos) - Faculdade de Letras, Universidade Federal de Minas Gerais, 2008.

KOCH, I.G.V. A coerência textual. São Paulo: Contexto, 1990.

O texto e a construção dos sentidos. São Paulo: Contexto, 1997.

. Desvendando os segredos do texto. 2. ed. São Paulo: Cortez, 2003.

. As tramas do texto. Rio de Janeiro: Nova Fronteira, 2008.

; BENTES, A. C.; CAVALCANTE, M. M. Intertextualidade: diálogos possíveis. São Paulo: Cortez, 2007.

KOMESU, F.C. Pensar em hipertexto. In: ARAÚJO, J.C; BIASI-

RODRIGUES, B. (Orgs.). Interação na internet: novas formas de usar a linguagem. Rio de Janeiro: Lucerna, 2005. p. 87-108.

KRISTEVA, J. Sèméiotikè: recherches pour une sémanalyse. Paris: Seuil, 1969.

SILVA, O. S. F. Nos labirintos da web: possibilidades de leitura e produção textual nos cenários digitais. Dissertação (Mestrado em Educação) Universidade do Estado da Bahia, 2006. 
XAVIER, A. C. O hipertexto na sociedade da informação: a constituição do modo de enunciação digital. Tese (Doutorado em Linguística) - IEL, Uninversidade Estadual de Campinas, 2002.

. Hipertexto e intertextualidade. Cad. est. ling., Campinas, v. 44, n. 1, p. 283-290, jan./jun, 2003.

- A dança das linguagens na web: critérios para a definição de hipertexto. In: SILVA, T.C.; MELLO, H. (Orgs.). Conferências do V Congresso Internacional da Associação Brasileira de Linguística. Belo Horizonte: FALE/UFMG, 2007. p. 199-210.

Recebido em 25/01/09. Aprovado em 10/07/09.

Title: Considerations on intertextuality in hypertexts

Author: Júlio César Araújo; Ana Cristina Lobo-Sousa

Abstract: Research studies that investigate hypertexts describe intertextuality as an inherent characteristic of these texts, since it takes the reader to a new text through the presence of hyperlinks. Considering intertextuality as a linguistic-discursive phenomenon that connects different speeches and is manifested in broad and restricted senses, this paper poses the question: "in which sense is the hypertext characterized as inherently intertextual?" In our analysis, we have observed that the intertextual phenomenon is described only as result of the juxtaposition of texts by hyperlinks, thus ignoring relations of meaning between them and existenting differences in comparison to how the same phenomenon would occur in written texts.

Keywords: intertextuality; hypertext; hyperlink.

Titre: Considérations sur l'intertextualité dans l'hypertexte

Auteur: Júlio César Araújo; Ana Cristina Lobo-Sousa

Résumé: Les travaux qui caractérisent l'hypertexte indiquent l'intertextualité comme une caractéristique inhérente, dans le sens de mener à un nouveau texte, dû à la présence des hyperlinks. Considérant l'intertextualité comme um phénomène linguistico-discursif qui met em rapport les dires et se manifeste dans um sens large et en sens restreint, ce travail se renseigne à propos de: "en quel sens on est en train de caractériser l'hypertexte comme intrinsèquement intertextuel". Dans notre réflexion, on se rend compte que le phénomène intertextuel étant décrit seulement en fonction de la juxtaposition de textes par des hyperlinks, ignorant les rapports de sens entre eux et les différences existantes entre ce qui se passait avec le propre phénomène dans le milieu du texte.

Mots-clés: intertextualité; hypertexte; hyperlink.

Título: Consideraciones sobre la intertextualidad en el hipertexto

ARAÚJO; LOBO-SOUSA - Considerações sobre a intertextualidade... 
Autor: Júlio César Araújo; Ana Cristina Lobo-Sousa

Resumen: Los trabajos que caracterizan el hipertexto apuntan a la intertextualidad como una característica que le es inherente, en el sentido de llevar a un nuevo texto, dada la presencia de los hiperlinks. Considerándose que la intertextualidad es un fenómeno linguístico-discursivo que relaciona los diceres y se manifiesta en sentido amplio y en sentido restricto, este trabajo indaga "en que sentido se está caracterizando el hipertexto como intrínsecamente intertextual". En nuestra reflexión, percibimos el fenómeno intertextual como siendo descrito apenas en función de la yuxtaposición de textos por los hiperlinks, desconsiderando las relaciones de sentido entre ellos y las diferencias existentes entre lo que ocurría con el mismo fenómeno en el ámbito del texto.

Palabras-clave: intertextualidad; hipertexto; hiperlink. 